\title{
EDITORIAL
}

\section{Surgical management of head and neck tumours during the SARS-CoV (COVID-19) pandemic}

\author{
Gestione chirurgica dei tumori testa e collo durante la pandemia da SARS-CoV \\ (COVID-19)
}

\author{
Mohssen Ansarin
}

Division of Otolaryngology and Head \& Neck Surgery, European Institute of Oncology IRCCS, Milan, Italy

The health emergency caused by the SARS-CoV (COVID-19) pandemic calls for the utmost commitment on the part of every member of the healthcare team and involves a reorganisation of the health system to meet exceptional care needs efficiently and effectively.

In Lombardy - one of the Italian regions most affected by this pandemic many public and private hospitals have been wholly reconverted to ensure the treatment of COVID-19 patients. At the same time, other "COVID-free" hospitals have been identified and designated to treat all other diseases and conditions safely. As a consequence of this reorganisation, specific cancer centres, including the European Institute of Oncology, have become regional reference "hubs" for the treatment of cancer patients. A series of organisational and clinical problems has therefore to be addressed as the number of patients to be evaluated and treated increases, while at the same time, it is necessary to ensure that the "hub" remains as "COVID-19-free" as possible over time.

These dedicated centres are employed in the treatment of patients referring from different areas, with a significant increase in workload, where, alongside the complexity of oncological disease, there is the overlapping problem of coronavirus infection.

The "urgency of treatment" of an oncology patient in this COVID-19 era becomes increasingly pressing when we add the distinctive degree of fragility of patients suffering from head and neck cancer - generally patients are debilitated by dysphagia-related malnutrition or by the disease itself, and on average require urgent treatments (less than 30 days) both due to the stage of the disease itself and due to the possible complications typical of this type of cancer: risk of suffocation arising from obstruction of the upper respiratory tract (larynx/pharynx) or the risk of haemorrhage which is often fatal.

The sudden increase in the number of patients entering the reference center is determined by the available resources, such as: the number of beds, availability of the operating room, availability of any intensive care units, and availability of diagnostic slots for staging examinations.

This discrepancy does not allow the requirements of the healthcare region to be fully met, and has led to an urgent remodelling of management and of certain concepts and recommendations that were considered the "gold standard" in times of "normality". Measures had to be undertaken in order to be able to respond to the national health emergency during a pandemic.

Ethically, it is challenging to define the right compromise between the necessary cancer treatments and the risk of infection. The biology of the tumour, the health of the patients, and the "viral" integrity (COVID-19-free nature) of the
Published on line: April 10, 2020

\section{Correspondence}

Mohssen Ansarin

Division of Otolaryngology and Head \& Neck Surgery, European Institute of Oncology IRCCS, via Ripamonti 435, 20141 Milan, Italy

E-mail: mohssen.ansarin@ieo.it

\section{Funding}

None.

\section{Conflict of interest}

The Author declares no conflict of interest.

How to cite this article: Ansarin M. Surgical management of head and neck tumours during the SARS-CoV (COVID-19) pandemic. Acta Otorhinolaryngol Ital 2020;40:87-89. https://doi. org/10.14639/0392-100X-N0783

(C) Società Italiana di Otorinolaringoiatria e Chirurgia Cervico-Facciale

\section{(c) $(1)(9)$}

This is an open access article distributed in accordance with the CC-BY-NC-ND (Creative Commons Attribution-NonCommercial-NoDerivatives 4.0 International) license. The article can be used by giving appropriate credit and mentioning the license, but only for non-commercial purposes and only in the original version. For further information: https:// creativecommons.org/licenses/by-nc-nd/4.0/deed.en 
hospital must be taken into account in treatment decisionmaking. This integrity must be tested over time to rule out the presence of the COVID-19 virus, to prevent the infectious disease from causing management difficulties ( $\mathrm{ad} \mathrm{hoc}$ measures should be provided for COVID-19 + patients), and major postoperative complications that are difficult to resolve, with consequent prolongations of hospital stay, increased bed occupancy, delays in starting any adjuvant therapies, as well as an increase in deaths.

It is also imperative to reduce the risk of in-hospital transmission of the virus among other patients and healthcare staff ${ }^{1}$.

In this perspective, measures are needed which provide support for a decision-making process that is as streamlined as possible and must be agreed and in harmony with the decisions of the crisis unit led by the hospital's medical directorate.

The following measures are the result of the experience gained day by day in an oncological hub addressing the emerging needs of head and neck cancer management, and of what has recently been published ${ }^{2-4}$.

\section{Action plan of an ENT regional cancer hub during the COVID-19 pandemic}

The individual patient performs all the procedures below. No accompanying person has the right of entry inside the centre in the absence of the patient's proven and demonstrable needs. All patients who are allowed entry must wear a surgical mask (provided at the entrance) that is removed only during the execution of the diagnostic investigations, in order not to transmit possible contagion as asymptomatic subject.

\section{Assessment of outpatients}

Before entering the facility, all patients undergo an initial triage where temperature is measured. After passing the first check, they are assessed oncologically. All clinical assessments such as laryngoscopy, nasal endoscopy, digital palpation of the oral cavity and oropharynx are considered as aerosol- and droplet-generating procedures (AGP), which require the adoption of medical devices by the examining doctor in the form of personal protective equipment (PPE): FFP2 mask, associated with a surgical mask, water-repellent disposable gown or apron, gloves, and protective goggles or visor.

\section{Staging}

One-day staging and pre-hospitalisation should be scheduled to minimise patient access to the hospital. Staging tests must be kept to the minimum necessary to accurately determine the correct extension of the tumour and the general condition of the patient. During the pre-hospitalization even in apyretic patients, pharyngeal swab and ad hoc blood tests are performed for the diagnosis of COVID-19: PCR, complete blood count with formula and LDH are conducted, and if found to be altered, a Chest CT scan should be carried out.

\section{Therapeutic planning (multidisciplinary team)}

It is essential to maintain the weekly frequency of multidisciplinary meetings. If necessary, these can be conducted in live streaming, by limiting their participation to those specialists who are indispensable, such as the surgeon, radiotherapist, medical oncologist, radiologist, and pathologist. Before hospitalisation, the multidisciplinary team must discuss all complex cases, such as patients with advanced malignancies, to decide and share the most appropriate treatment plan. On the other hand, cases in which therapy is well standardised and consolidated (e.g., early laryngeal or oral tumours, nasopharyngeal cancers) may not need to be discussed in the multidisciplinary meeting.

\section{Treatments}

It is advisable to delay the treatment of low-risk tumours, for example, differentiated thyroid cancers; reduce, where possible, the duration of surgery by choosing a minimallyinvasive rather than an open approach (e.g., in borderline laryngeal or paranasal sinus tumours); choose transoral surgery vs. major surgery (e.g. in borderline cancers of the oral cavity); reconstruct surgical defects with local flaps rather than revascularised flaps; minimise the presence in the operating room of people not involved in surgical and anaesthesiological procedures (fellows, attendees, and clinical observers).

\section{Hospital stay}

All patients are to be considered as possible healthy carriers and are therefore obliged to wear a surgical mask. Patients with a tracheotomy have a high droplet production and the healthcare professional must pay scrupulous attention when carrying out any actions, manoeuvres, positioning, procedures etc. on the patient. So, the patient on the ward, with a tracheotomy, must be managed with suitable PPE: FFP2 mask, associated with a surgical mask, waterrepellent disposable gown or apron, gloves, and protective goggles or visor ${ }^{3}$. 


\section{Follow-up}

All patients with scheduled periodic checks should be contacted by telephone by a staff doctor; if the patient is asymptomatic, the clinical check must be postponed for at least six months, and the patient should be asked to communicate any adverse events by telephone or email. It is also advisable to reduce post-operative clinical checks by organising telephone or video call contacts, where possible. This editorial aims to share the experience acquired in a short time in a Lombardy cancer hub, pointing out the pitfalls and difficulties that head and neck surgeons may encounter daily, and indicating how to deal with them throughout this health emergency.

\section{References}

1 Torretta S, Gaini LM, Pignataro L. Why Italian ENT physicians should be aware of SARS-CoV-2. Acta Otorhinolaryngol Ital 2020;40:152-3. https://doi.org/10.14639/0392-100X-N0738

2 Givi B, Schiff BA, Chinn SB, et al. Safety recommendations for evaluation and surgery of the head and neck during the COVID-19 Pandemic. JAMA Otolaryngol Head Neck Surg 2020 Mar 31. [Epub ahead of print]. https://doi.org/10.1001/jamaoto.2020.0780

3 ENT UK. Guidance for ENT during the COVID-19 pandemic. https:// www.entuk.org/guidance-ent-during-covid-19-pandemic (Accessed April 3, 2020).

4 Tay JK, Khoo ML-C, Loh WS. Surgical considerations for tracheostomy during the COVID-19 pandemic: lessons learned from the severe acute respiratory syndrome outbreak. JAMA Otolaryngol Head Neck Surg 2020 Mar 31. [Epub ahead of print]. https://doi.org/10.1001/ jamaoto.2020.0764 